\title{
Efecto de polímeros algales sobre la productividad de uva de mesa bajo condiciones de riego deficitario
}

\author{
Lorgio E. Aguilera ${ }^{*}$, Nancy P. Chandía ${ }^{2}$, Paula Needham ${ }^{2}$, y Carmen Alvarez ${ }^{2}$ \\ (1) Departamento de Biología, Facultad de Ciencias, Universidad de La Serena, La Serena, Chile \\ (correo-e: laguiler@userena.cl). \\ (2) Departamento de Biología Marina, Facultad de Ciencias del Mar, Universidad Católica del Norte, Coquimbo, Chile \\ (correo-e: nchandia@ucn.cl,needpaula@gmail.com, calvarezr@ucn.cl).
}

${ }^{*}$ Autor a quien debe ser dirigida la correspondencia.

Recibido Ene. 22, 2021; Aceptado Mar. 13, 2021; Versión final May. 18, 2021, Publicado Ago. 2021

\begin{abstract}
Resumen
El objetivo de este estudio es evaluar el efecto de una mezcla de alginato y ulvano sobre la productividad de uva de mesa cultivada bajo riego deficitario. En un predio agrícola, se eligieron al azar 24 plantas de Vitis vinifera var Thompon Seedless. A la mitad de las plantas con riego normal y con riego deficitario se les adicionó mensualmente a sus suelos $500 \mathrm{~g} / \mathrm{m}^{3}$ de la mezcla durante toda la temporada 2019-2020. Los resultados muestran que el riego deficitario más la adición de hidrogel algal aumentaron la producción y el peso de los racimos de uva en un $18,5 \%$ y un $6,4 \%$, respectivamente, en comparación a las plantas solo con riego deficitario. La adición de hidrogel algal mejoró la fertilidad de los suelos y estimuló el crecimiento de bacterias y hongos, principalmente, en los suelos sin restricción hídrica. Se concluye que el uso de hidrogel algal en el cultivo de vides bajo riego deficitario mejora la productividad del cultivo.
\end{abstract}

Palabras clave: alginato; ulvano; Vitis vinifera; riego deficitario; microrganismos

\section{Effect of algal polymers on table grape productivity under deficit irrigation conditions}

\begin{abstract}
The main objective of this research study was to assess the effect of an alginate and ulvan mixture on the productivity of table grapes grown under deficit irrigation conditions. Twenty-four Vitis vinifera var Thompon Seedless plants were randomly selected in a farm field. A mixture of algae polymers $(500 \mathrm{~g} / \mathrm{m} 3)$ were added monthly (2019-2020 season) to the soils of half of the plants with normal irrigation and with deficit irrigation. The results show that deficit irrigation along with the addition of algal hydrogel increased grape bunch production and weight by $18.5 \%$ and $6.4 \%$, respectively, when compared to plants with deficit irrigation only. The addition of algal hydrogel improved soil fertility and stimulated bacterial and fungal growth mainly in soils without water restriction. It is concluded that algal hydrogel improves vine crop productivity under deficit irrigation conditions.
\end{abstract}




\section{INTRODUCCIÓN}

En Chile, la baja disponibilidad de agua para el riego que enfrenta la zona centro-norte, donde se concentra la viticultura del país (ODEPA, 2017), obliga a los productores de uva la incorporación de nuevas técnicas agronómicas modernas para administrar los escasos recursos hídricos. Debido a que las tendencias climáticas indican que las condiciones de aridización del país continuarán en el futuro (Santibáñez et al., 2014) se espera que la baja disponibilidad de agua para riego sea permanente y el cultivo de uva tenga que adaptarse a estas condiciones. La uva de mesa es la principal especie frutal en Chile, con una superficie de aproximadamente 55.000 ha, distribuida principalmente entre la región de Atacama y del Maule, colocando a Chile entre los principales productores del hemisferio sur (Ferreyra et al., 2001). Dentro de sus variedades destaca Thompson Seedless, por ser una de las más importantes en términos de volumen de producción y exportación, debido principalmente a su alta demanda y precios que alcanzan en el mercado exterior (Ferreyra et al., 2001).

Un aspecto para considerar es que una importante proporción de los cultivos de uva en el norte de Chile, se han establecido en suelos arenosos con baja capacidad de retención hídrica tales como las partes bajas de valles transversales y de cuencas hidrográficas (Apey, 2019), lo cual maximiza el déficit de agua para los cultivos, ya que el agua irrigada percola rápidamente más allá de la zona de raíces (Yu et al., 2017), lo cual provoca un bajo desarrollo vegetativo, baja productividad, calibres pequeños y mala calidad de la fruta en general.

Estos problemas requieren del uso de aproximaciones integradas que incluyan técnicas agronómicas de uso eficiente del agua y prácticas de manejo apropiadas (Chaves et al., 2010). El uso de polímeros sintéticos que absorben agua (i.e., hidrogeles) como las poliacrilamidas mejoran la capacidad del suelo para retener el agua para el crecimiento y producción agrícola (Milani et al., 2017). Esta retención hídrica, bajo condiciones de sequía y suelos arenosos, mitiga el estrés hídrico de las plantas y, en consecuencia, permiten intervalos más largos entre riegos consecutivos y mejoran la tasa de crecimiento y el rendimiento de los cultivos (Taban y Mavahedi, 2006). Sin embargo, en Chile, los hidrogeles sintéticos no se han usado ampliamente a escala de campo en el cultivo de la vid, posiblemente debido a los altos costos y/o porque los agricultores están adoptando medidas más sustentables que protejan al medio ambiente y están reemplazando parcial o totalmente los insumos sintéticos por alternativas más ecológicas.

Las macroalgas marinas biosintetizan polímeros tales como agaranos, carragenanos, fucanos, alginatos, ulvanos, entre otros (Khan et al., 2009). Estos polímeros presentan una variedad de actividades biológicas sobre plantas y animales (Michalack et al., 2016). Para la agricultura, son de particular interés aquellos que tienen propiedades de absorber agua como el alginato y aquellos que actúan como elicitores activando respuestas defensivas en las plantas contra patógenos o plagas como el ulvano (Khan et al., 2009). Los polisacáridos, como el alginato, presentes principalmente en algas pardas, son polímeros biocompatibles que forman hidrogeles más estudiados (Holdt y Kraan, 2011). No son tóxicos, son solubles en agua, son biodegradables y presentan grupos carboxílicos como grupos funcionales (Philips y Williams, 2009). El ulvano es un polímero producido por algas verdes con reconocida actividad elicitora en las plantas. Está compuesto principalmente de ramnosa, ácidos glucurónico e idurónico y xilosa, encontrándose la mayoría de las veces distribuido en unidades repetidas de disacáridos (Jaulneau et al., 2010).

Dado los importantes efectos que podrían tener los polímeros algales alginato y ulvano sobre el cultivo de vides en suelos con baja capacidad de retención hídrica y en un escenario de escasez de agua, producto de prolongadas sequias, en este estudio se investigó el efecto combinado de alginato y ulvano sobre la productividad de uva de mesa (Vitis vinifera var Thompson Seedless) cultivadas en suelos arenosos bajo riego deficitario.

\section{MATERIALES Y MÉTODOS}

El estudio se realizó en un cultivo productivo de uva de mesa Vitis vinifera var. Thompson Seedless, ubicado en Paihuano, Provincia del Elqui, región de Coquimbo, Chile (2959'03" S - 70³2'45" O). Las plantas estaban dispuestas en un marco de plantación de $2 \mathrm{~m} \times 3 \mathrm{~m}$, se encontraban podadas a dos brazos con 8 cargadores y 6 yemas por cargador, tenían un riego por goteo de $2 \mathrm{~L} / \mathrm{h}$ con 3 goteros por planta y eran fertilizadas con una dosis de 95, 15 y $78 \mathrm{Kg} / \mathrm{ha}$ de N, P, K, respectivamente, a partir de la fenofase de floración hasta cosecha.

\section{Obtención y formulación de hidrogel algal (HGA)}

El hidrogel algal utilizado en este estudio correspondió a la mezcla de los polímeros algales alginato de sodio y ulvano, en proporciones de 9:1. El alginato de sodio se obtuvo a partir de un subproducto industrial de frondas y estipes de Lessonia berteroana/spicata (ex Lessonia nigrescens) y Lessonia trabeculata, denominado "harina", proporcionado por la empresa KAY Ltda. Para la extracción de alginato, la harina se 
despigmentó con una mezcla de formaldehido y etanol y se trató con éter de petróleo para la extracción de lípidos. Luego fueron sometidas a extracciones con soluciones de carbonato de sodio al $3 \%$ a $50^{\circ} \mathrm{C}$ con agitación mecánica constante por $5 \mathrm{~h}$. Posteriormente, la mezcla resultante fue centrifugada a $3000 \mathrm{rpm}$ por 20 min. El sobrenadante de la extracción se dializó por 72 h y se concentró en un evaporador rotatorio. La solución concentrada se precipitó en etanol y se separó mediante filtración (Venegas et al., 1993).

El ulvano se obtuvo de algas verdes del género Ulva colectadas desde el intermareal de la bahía La Herradura, región de Coquimbo, Chile ( $29^{\circ} \quad 58^{\prime} \mathrm{S}, 71^{\circ} \quad 20^{\prime}$ O). Para la extracción de ulvano se utilizó la metodología modificada de Robic et al., (2009). Las láminas de Ulva se secaron a temperatura ambiente y se molieron a una granulometría $\leq 2,0 \mathrm{~mm}$. Luego se despigmentaron con etanol $70 \%$ durante $1 \mathrm{~h} \mathrm{a} 75^{\circ} \mathrm{C}$. Posteriormente, las algas fueron sometidas a extracciones sucesivas en solución acuosa a $85^{\circ} \mathrm{C}$ con agitación constante por $5 \mathrm{~h}$. El extracto líquido obtenido fue centrifugado a $2500 \mathrm{rpm}$ por $15 \mathrm{~min}$ y el sobrenadante se dializó por 72 h. Finalmente, el polímero dializado se concentró en un evaporador rotatorio, se precipitó en etanol y se separó mediante filtración. La verificación de la identidad de los polímeros se realizó en la Facultad de Química y Biología de la Universidad de Santiago de Chile, mediante métodos espectrofotométricos para determinar la composición química y espectroscopia de Infrarrojo con Transformada de Fourier.

\section{Diseño experimental y medición de variables}

Para evaluar el efecto de la adición de hidrogel algal y el riego deficitario sobre la productividad de uva de las plantas de vid, se implementó un diseño experimental que consistió en elegir al azar 24 plantas de vid dentro del cultivo. A 12 de las plantas se les adicionó HGA en una dosis equivalente a $500 \mathrm{~g} / \mathrm{m}^{3}$ suelo, en la zona radicular entre 0 y $20 \mathrm{~cm}$ de profundidad bajo la línea de gotero. A 6 de estas plantas y a otras 6 que no recibieron $\mathrm{HGA}$, se regaron con un $67 \%$ del volumen de riego definido por la evapotranspiración del cultivo $(E T C)$, resultando los siguientes tratamientos: tratamiento 1 (control): 100\% reposición ETc, tratamiento 2: 100\% reposición ETc + HGA, tratamiento 3: 67\% reposición ETc y tratamiento 4:67\% reposición ETc + HGA. La adición de HGA fue al inicio de cada mes a lo largo de toda la temporada (agosto 2019 - febrero 2020). Los niveles de agua del suelo se determinaron mediante sondas FDR (Frequency Domaine Reflectometry) 5TE Morpho instaladas a $20 \mathrm{~cm}$ de profundidad en la zona radicular de la planta y se expresaron como contenido volumétrico de agua del suelo $\left(\mathrm{m}^{3} / \mathrm{m}^{3}\right)$.

Para determinar el contenido de macro y micronutrientes y la abundancia de bacterias, hongos y nematodos, se realizó un muestreo compuesto de suelos rizosféricos bajo la canopia de todas las plantas por tratamiento durante el período de cosecha (enero del 2020). Para cada tratamiento se colectó un volumen compuesto de $2,0 \mathrm{Kg}$ de suelos. Las muestras fueron transportados al laboratorio y cada muestra se subdividió en dos grupos de porciones iguales. Un grupo de las porciones se usó para los análisis microbianos, que consistieron en estimar la abundancia de bacterias aerobias-mesofílicas-heterotróficas, hongos filamentosos viables utilizando el método de dilución y recuento en placa descrito por Parkinson et al., (1971) y modificado por Aguilera et al., (2016) y los nemátodos móviles totales a través del embudo de Baerman (Hernández-Ochandia et al., 2016). El segundo grupo de porciones se envió un laboratorio certificado para análisis fisicoquímicos del suelo. En las porciones de las muestras del tratamiento control del primer grupo se procedió a determinar el metabolismo del suelo de acuerdo al procedimiento descrito por Badía y Marti, (2003).

\section{Análisis de datos}

Para evaluar el efecto de los tratamientos sobre los parámetros productivos de la uva de mesa se realizó un análisis de varianza de una vía. Los datos de productividad, análisis físicoquímicos y de microorganismos del suelo se relacionaron mediante la prueba de correlación de Pearson. Antes de los análisis, y cuando fue necesario, algunos datos se transformaron mediante el logaritmo natural para cumplir con los supuestos de normalidad. La significancia se estableció en un $p<0,05$. Los análisis se realizaron en $R$ ( $R$ Development Core Team, 2013) utilizando la interfaz implementada en el software estadístico InfoStat (v. 2013; http://www.infostat.com.ar). Los datos se proporcionan como medias \pm 1 error estándar.

\section{RESULTADOS Y DISCUSIÓN}

El riego deficitario de las vides (ETc 67\%) disminuyó el contenido volumétrico de agua (CVA) del suelo en un $55,7 \%$, en promedio. En cambio, el tratamiento ETc $67 \%$ más la adición de HGA a los suelos disminuyo el CVA en la estrata superficial en un $42,7 \%$, lo que significó que estos suelos retuvieran un $13 \%$ más del CVA en comparación a los suelos con riego deficitario y sin adición de HGA. Este 13\% de diferencia se traduce en que los suelos con déficit hídrico más HGA retuvieron 32,63 L de agua más por metro cúbico de suelo que los suelos con riego deficitario sin adición de HGA. La adición de HGA en suelos con un $100 \%$ de la reposición de la ETc no afectó el CVA (Tabla 1). 
Se ha descrito que el alginato (un componente del HGA), interactúa con iones metálicos en el suelo y forman complejos de alto peso molecular que absorben humedad, se hinchan y retienen agua, lo cual mejora la estructura del suelo. Esto resulta en una mejor aireación y capilaridad de los poros del suelo, que a su vez estimula el crecimiento del sistema radicular de las plantas y aumenta la actividad microbiana del suelo (Moore, 2004). Desde el punto de vista agronómico, se encontró que los suelos controles presentaban niveles altos de materia orgánica $(6,1 \%)$, concentraciones adecuadas de macronutrientes y niveles entre adecuados a altos para los micronutrientes (Tabla 1). Además, estos suelos se clasificaron como ligeramente alcalinos y levemente salinos por sus valores de $\mathrm{pH}$ y conductividad eléctrica, respectivamente. Estos resultados significan, que los suelos presentan un nivel de fertilidad que permite un adecuado crecimiento y desarrollo del cultivo de uva de mesa estudiado.

La adición de HGA en los suelos de las plantas sin restricción hídrica tuvo un efecto positivo sobre la fertilidad. La materia orgánica incrementó en un 34,4\%, los macronutrientes incrementaron en promedio un $50,2 \%$, los micronutrientes, a excepción del hierro, incrementaron en promedio en un $47,5 \%$, el pH no varió y la conductividad eléctrica incrementó en un $8,8 \%$, manteniendo la condición de suelos para este último parámetro en levemente salino (Tabla 1). En cambio, el riego deficitario, tuvo efectos diversos sobre los parámetros fisicoquímicos del suelo. Este no afectó el pH, disminuyó la concentración del fósforo, potasio y hierro en un $15,1 \%$ en promedio, redujo la conductividad en un $14,7 \%$ e incrementó el porcentaje de la materia orgánica y la concentración N, Mn, Zn, Cu y B en un 40,5\% en promedio. Debido a que los nutrientes son administrados por el riego tecnificado del cultivo, es razonable suponer que al disminuir el volumen de riego también disminuyan los niveles de nutrientes aplicados, lo cual concuerda para los parámetros fisicoquímicos que disminuyeron sus concentraciones. Sin embargo, sorprendentemente, la disminución del riego también se relacionó con el aumento de la materia orgánica y del $\mathrm{N}, \mathrm{Mn}, \mathrm{Zn}$ y $\mathrm{B}$. En este caso, un menor volumen de riego se traduciría en una menor percolación de líquidos y por lo tanto una menor pérdida de estos nutrientes por lixiviación a capas más profundas de suelos, lo cual finalmente permitiría mantener y concentrar estos nutrientes en las capas más superficiales del suelo.

La adición de HGA a los suelos con restricción hídrica tuvo efectos positivos y negativos sobre los parámetros fisicoquímicos del suelo, en comparación a los suelos sólo con restricción hídrica. Se encontró que incrementaron los niveles de fósforo, potasio, hierro, cobre, $\mathrm{pH}$ y conductividad eléctrica; en cambio, disminuyeron los niveles de materia orgánica, nitrógeno, manganeso, cobre y zinc (Tabla 1). Sin embargo, la disminución observada no afectaría la nutrición de las plantas ya que aún sus concentraciones se mantienen en niveles adecuados a altos. En la Tabla 1, los valores entre paréntesis corresponden al incremento (+) o disminución (-) del valor respecto de los controles, expresado en porcentaje, ETc es la evapotranspiración del cultivo, y HGA es hidrogel algal.

Tabla 1: Características fisicoquímicas de suelos de Vitis vinifera var Thompson Seedless cultivadas en el Valle de Pisco Elqui, Paihuano, Chile.

\begin{tabular}{|l|c|c|c|c|}
\hline Parámetros químicos & $\begin{array}{c}\text { Tratamiento 1 } \\
\text { (Control, 100\% ETc) }\end{array}$ & $\begin{array}{c}\text { Tratamiento 2 } \\
(100 \% \text { ETc + HGA) }\end{array}$ & $\begin{array}{c}\text { Tratamiento 3 } \\
\text { (67\% ETc) }\end{array}$ & $\begin{array}{c}\text { Tratamiento 4 } \\
(67 \% \text { ETC + HGA) }\end{array}$ \\
\hline Materia orgánica $(\%)$ & 6.1 & $8.2(+34,4 \%)$ & 9.2 & $6.1(-33,7 \%)$ \\
\hline Nitrógeno disponible $(\mathrm{mg} / \mathrm{Kg})(\mathrm{N})$ & 48 & $64(+33,3 \%)$ & 71 & $54(-23,9 \%)$ \\
\hline Fósforo disponible $(\mathrm{mg} / \mathrm{Kg})(\mathrm{P})$ & 53 & $79(+49,1 \%)$ & 38 & $61(+60,5 \%)$ \\
\hline Potasio disponible $(\mathrm{mg} / \mathrm{Kg})(\mathrm{K})$ & 334 & $562(+68,3 \%)$ & 324 & $405(+25,0 \%)$ \\
\hline Hierro disponible $(\mathrm{mg} / \mathrm{Kg})(\mathrm{Fe})$ & 8.5 & $7(-17,6 \%)$ & 7.3 & $8.5(+14,1 \%)$ \\
\hline Manganeso disponible $(\mathrm{mg} / \mathrm{Kg})(\mathrm{Mn})$ & 25 & $43.8(+75,2 \%)$ & 42.4 & $27.3(-36,3 \%)$ \\
\hline Zinc disponible $(\mathrm{mg} / \mathrm{Kg})(\mathrm{Zn})$ & 6.8 & $9.6(+41,2 \%)$ & 7.5 & $7.8(-4,0 \%)$ \\
\hline Cobre disponible $(\mathrm{mg} / \mathrm{Kg})(\mathrm{Cu})$ & 2.5 & $3.7(+48,0 \%)$ & 4.2 & $4.3(-2,4 \%)$ \\
\hline Boro disponible $(\mathrm{mg} / \mathrm{Kg})(\mathrm{B})$ & 3.1 & $3.9(+25,8 \%)$ & 3.3 & $2.6(-21,2 \%)$ \\
\hline pH (agua, relación 1:2,5) & 7.5 & $7.5(0,0 \%)$ & 7.5 & $7.6(+1,3 \%)$ \\
\hline Cond. eléctrica en extracto $(\mathrm{dS} / \mathrm{m})$ & 3.4 & $3.7(+8,8 \%)$ & 2.9 & $4.2(+44,8 \%)$ \\
\hline Contenido volumétrico agua $\left(\mathrm{m}^{3} / \mathrm{m}^{3}\right)$ & 0,248 & $0,243(-2,0 \%)$ & 0,110 & $0,142(+29,1 \%)$ \\
\hline
\end{tabular}


El aumento de la conductividad cambió la salinidad del suelo desde levemente salino a moderadamente salino. Aunque Vitis vinifera puede tolerar y desarrollarse a elevadas salinidades (entre 1,9 y $12,3 \mathrm{dS} / \mathrm{m}^{-1}$, Fisarakis y Stavrakas, 2001), este es un aspecto importante de tener en cuenta, debido a los efectos negativos que pueden tener el aumento de sales en los suelos y en los cultivos.

\section{Abundancia de microorganismos del suelo}

La abundancia de bacterias, hongos y nematodos de los suelos controles se encontró dentro de los rangos descritos para suelos agrícolas y regionales (Aguilera et al., 2016). La adición de HGA a los suelos de las plantas sin restricción hídrica tuvo un efecto positivo sobre las bacterias y hongos, incrementando su abundancia en un $300 \%$ y $150 \%$, respectivamente, como se observa en la Tabla 2 . En la Tabla 2, los valores entre paréntesis corresponden al incremento (+) o disminución (-) del valor respecto del control, expresado en porcentaje, ETc es la evapotranspiración del cultivo, HGA es hidrogel algal, y ufc corresponde a unidades formadoras de colonias. En cambio, este tratamiento afectó negativamente el número de nemátodos del suelo, disminuyendo su abundancia en un 12,8\%. Igualmente, el riego deficitario afectó a los tres parámetros microbiológicos, disminuyendo sus abundancias con relación al control. En cambio, la adición de HGA a los suelos con restricción hídrica tuvo un marcado efecto positivo e incremento la abundancia de bacterias y hongos en dos y un orden de magnitud y, por el contrario, disminuyó la concentración de nematodos del suelo en un $48,4 \%$.

Tabla 2: Parámetros microbiológicos de suelos de Vitis vinifera var Thompson Seedless cultivadas en el Valle de Pisco Elqui, Paihuano, Chile.

\begin{tabular}{|l|c|c|c|c|}
\hline Parámetros microbiológicos & $\begin{array}{c}\text { Tratamiento 1 } \\
\text { (Control, 100\% ETc) }\end{array}$ & $\begin{array}{c}\text { Tratamiento 2 } \\
(100 \% \text { ETc }+ \text { HGA })\end{array}$ & $\begin{array}{c}\text { Tratamiento 3 } \\
(67 \% \text { ETc) }\end{array}$ & $\begin{array}{c}\text { Tratamiento 4 } \\
(67 \% \text { ETc + HGA) }\end{array}$ \\
\hline Bacterias (ufc/g suelo) & $3.0 \times 10^{7}$ & $1.2 \times 10^{8}(+300 \%)$ & $6.8 \times 10^{5}$ & $8.6 \times 10^{7}(+12.547 \%)$ \\
\hline Hongos (ufc/g suelo) & $5.6 \times 10^{6}$ & $1.4 \times 10^{7}(+150 \%)$ & $5.6 \times 10^{5}$ & $9.0 \times 10^{6}(+1.507 \%)$ \\
\hline Nematodos (No/100 g suelo) & $9.4 \times 10^{1}$ & $8.2 \times 10^{1}(-12,8 \%)$ & $6.4 \times 10^{1}$ & $3.3 \times 10^{1}(-48,4 \%)$ \\
\hline
\end{tabular}

Es probable que el HGA adicionado a los suelos haya sido usado por las bacterias y hongos como fuente de carbono para su crecimiento. Vitthalrao et al., (2010) encontraron un aumento en las poblaciones microbianas cuando adicionaron alginato a suelos agrícolas arenosos. Estos son resultados interesantes, ya que se ha reportado que la adición de hidrogeles sintéticos al suelo, como los derivados de poliacrilamidas, reducen las bacterias totales, la biomasa microbiana total y la biomasa total de hongos, en relación a los tratamientos control (Sojka y Entry, 2000). Además, en nuestro estudio, se encontró que la adición de HGA afectó positivamente el metabolismo del suelo. La adición de HGA aumento en un $203,8 \%$ la producción de $\mathrm{CO}_{2}$ del suelo a las 48 h de aplicación, en comparación al suelo control sin adición de HGA (Fig. 1).

Es probable que las bacterias y hongos de los suelos rizosféricos de los cultivos de vid estudiados puedan degradar los polímeros que conforman el HGA, y resulten en la formación de azúcares reductores, que son metabolizados y en consecuencia induzcan el crecimiento de la microbiota. Por el contrario, la adición de HGA a los suelos con y sin restricción hídrica afectó por igual a los nematodos, disminuyendo de manera importante su abundancia (Tabla 2).

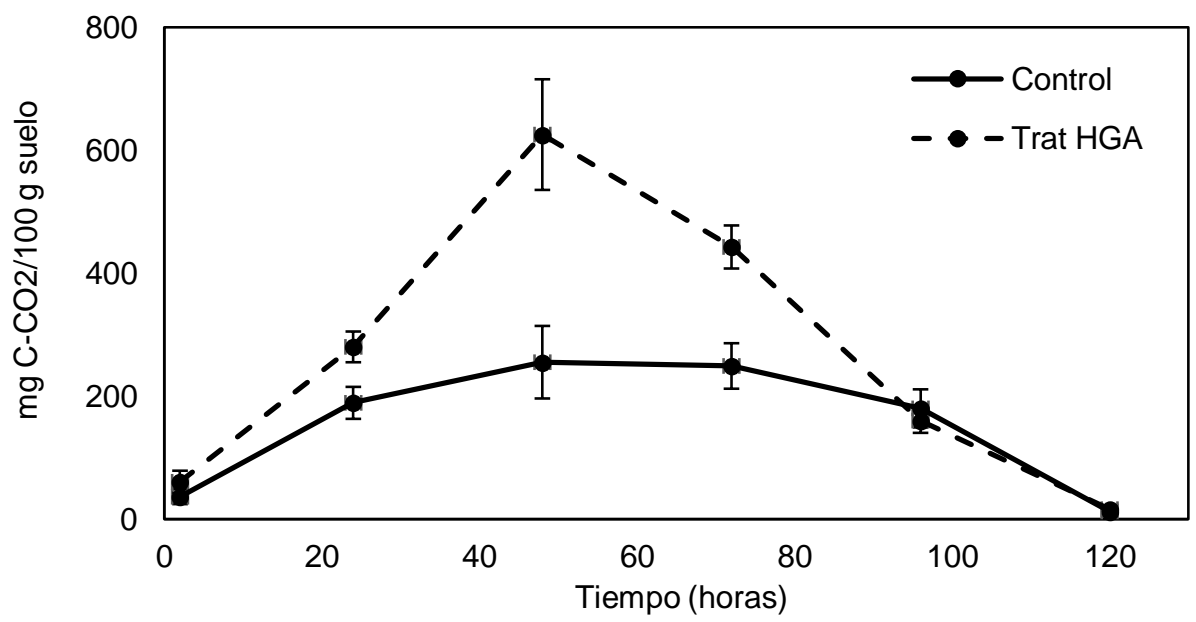

Fig. 1: Evolución de $\mathrm{CO}_{2}$ a lo largo del tiempo en suelos adicionados (línea discontinua) y sin adición (línea continua) de HGA en dosis de $500 \mathrm{mg} / \mathrm{Kg}$ de suelo. Los puntos son el promedio de 3 réplicas y las barras son el error estándar. 
Se ha reportado que la adición de materia orgánica en forma de abono, estiércol u otros materiales orgánicos al suelo disminuyen las poblaciones de nemátodos de manera indirecta, ya que las enmiendas orgánicas incrementan las poblaciones de microorganismos antagonistas de los nemátodos (Widmer et. al., 2002). Estos resultados permiten sugerir que el HGA tendría un efecto dual sobre la microbiota del suelo: por un lado estimula el crecimiento de bacterias y hongos benéficos del suelo y por otro inhibiría el desarrollo de nematodos.

\section{Parámetros productivos}

La adición de HGA no tuvo un efecto significativo sobre el número de racimos de uva en las plantas con un $100 \%$ de la reposición de la ETc, en relación a las plantas control (Fig. 2). En cambio, el riego deficitario disminuyó significativamente el número de racimos en las plantas sin adición de HGA, pero bajo esta condición, la adición de HGA incrementó significativamente el número de racimos por planta (Fig. 2).

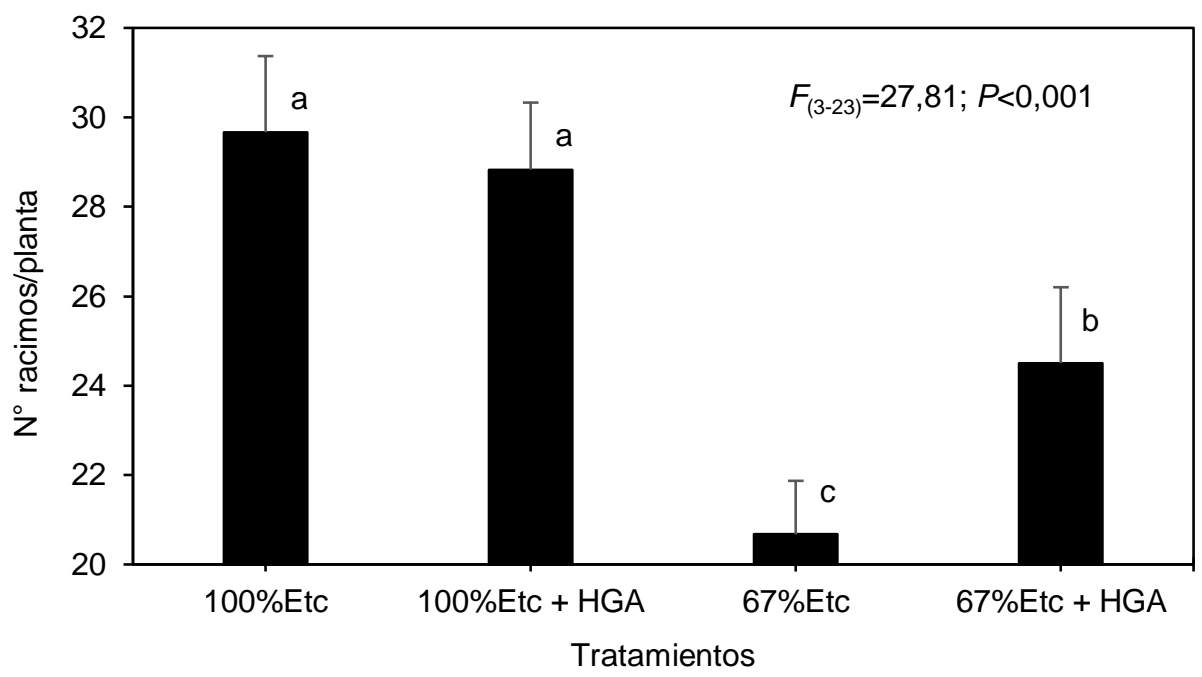

Fig. 2: Producción de número de racimos por planta de Vitis vinifera var Thompson Seedless. Las barras representan el promedio de 6 réplicas. Barras con diferentes letras son diferentes según la prueba a posteriori.

El peso de los racimos de uva tampoco fue afectado significativamente por la adición de HGA a las plantas, en la condición de $100 \%$ de reposición de la ETc, en relación al control (Fig. 3). En cambio, el riego deficitario también disminuyó significativamente el peso de los racimos en las plantas sin adición de HGA. Sin embargo, bajo la condición de riego deficitario, la adición de HGA incrementó significativamente el peso de los racimos, equivalente a una masa de $32 \mathrm{~g}$. La masa de los racimos se correlacionó positiva y significativamente con la abundancia bacteriana de los suelos $(r=0,68 ; P=0,01)$.

El sistema radicular de las vides es colonizado naturalmente por una microbiota compleja y diversa (Barata et al., 2012), que modula el crecimiento y productividad de la planta (Gilbert et al., 2014). Sin embargo, la diversidad y abundancia de hongos y bacterias son reducidos drásticamente en la medida que incrementa la aridez del suelo (Maestre et al., 2015). La adición de alginato al suelo podría contrarrestar el efecto del estrés hídrico sobre la comunidad microbiana asociada al sistema radicular de vides, ya que se ha encontrado que la aplicación de alginato al suelo estimula el crecimiento de microorganismos benéficos y la secreción de sustancias por parte de los microorganismos que mejoran las condiciones físicas del suelo (Liu y Howell, 2020). Ishii et al., (2000), encontraron que oligosacáridos derivados de la degradación enzimática del ácido algínico aumentaron significativamente el crecimiento micelial e infectividad de hongos micorrizas arbusculares.

También se ha reportado que el alginato se ha usado exitosamente como molécula promotora del crecimiento de las plantas en su forma despolimerizada como oligómeros de bajo peso molecular. La aplicación de estos oligómeros sobre los cultivos reduce el efecto del estrés e incrementan el crecimiento de las plantas (Hien et al., 2000). Debido a que en nuestro estudio se observó un efecto positivo del HGA sobre bacterias, hongos y metabolismo del suelo, se podría hipotetizar que el alginato es degradado por la microbiota del suelo a oligómeros que tendrían un efecto positivo sobre la producción de bayas en Vitis vinifera cuando esta se cultiva bajo riego deficitario. 
A partir de las plantas del tratamiento control se estimó una producción de uva de $16.251 \mathrm{~kg} / \mathrm{ha}$. Este nivel de producción fue fuertemente afectado por el riego deficitario, disminuyendo la producción de uva en 5.405 $\mathrm{Kg} / \mathrm{ha}$. Sin embargo, la adición de HGA a los suelos con restricción hídrica, permitió revertir la disminución de masa de uvas en un $41,5 \%$, produciéndose $10,327 \mathrm{Kg} / \mathrm{ha}$ en comparación a los $8,082 \mathrm{Kg} / \mathrm{ha}$ producidos por las plantas con restricción hídrica no adicionadas con HGA.

Estos resultados son equivalentes a producir más de 273 cajas de uva exportables si se aplica HGA en los predios con restricción hídrica, en comparación a cultivos que no usen este tipo de hidrogel natural retenedor de humedad en los suelos y potencial estimulador de microorganismos que favorecen el crecimiento vegetal. Por último, la eficiencia del uso del agua agronómico fue mayor en el tratamiento con restricción hídrica más HGA $\left(2,63 \mathrm{Kg} / \mathrm{m}^{3}\right)$, en comparación a los otros 3 tratamientos (incluyendo al control), lo cual resultó en aumentar la productividad por metro cúbico de agua aplicada, aunque el número de cajas exportables sea menor que con el tratamiento control.

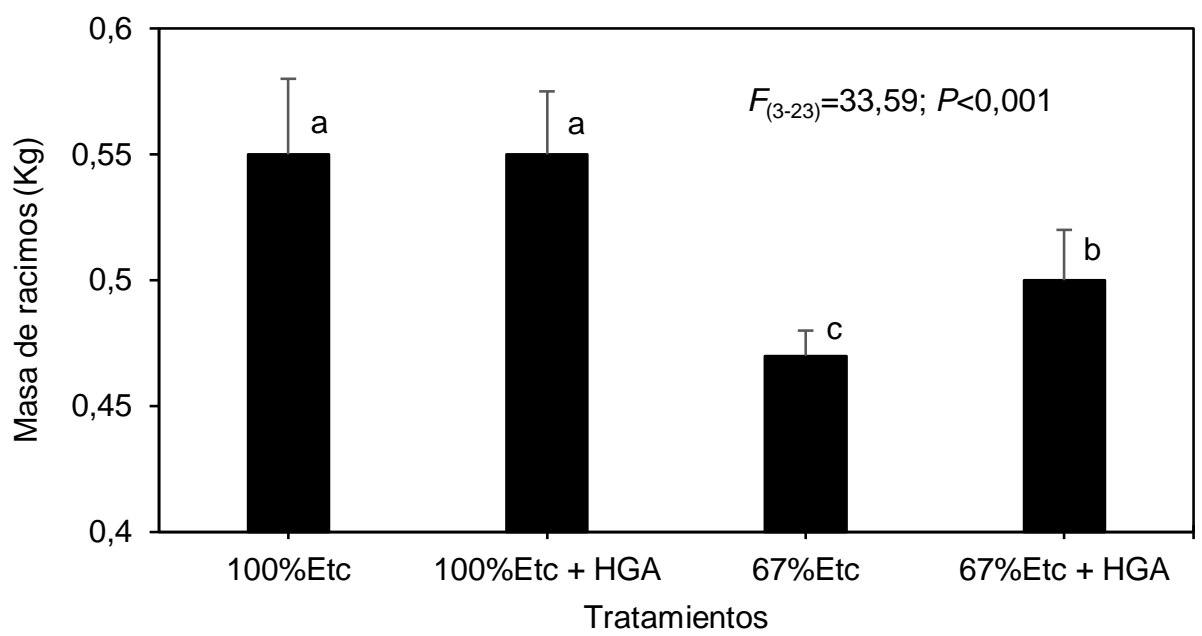

Fig. 3: Masa de racimos de Vitis vinifera var Thompson Seedless. Las barras representan el promedio de 30 réplicas. Barras con diferentes letras son diferentes según la prueba a posteriori.

\section{CONCLUSIONES}

De acuerdo a los resultados de este estudio el HGA mejoró los niveles de algunos nutrientes de los suelos cultivados con Vitis vinifera var. Thompson Seedless, bajo riego deficitario. Además, este polímero algal presentó un efecto dual sobre los microorganismos del suelo, estimulando por una parte el crecimiento y actividad de microorganismos benéficos y por otra disminuyendo el desarrollo de nematodos móviles. El hidrogel algal tuvo un efecto positivo sobre la productividad de uva de mesa estudiada, permitiendo obtener una mayor producción de uva en plantas cultivadas bajo restricción hídrica en comparación a plantas sin adición del polímero algal.

\section{AGRADECIMIENTOS}

Los autores agradecen al Gobierno Regional de Coquimbo por el financiamiento de este trabajo mediante la adjudicación del Proyecto del Fondo de Innovación Competitiva FIC-R Código BIP 30485882-0 "Producción de hidrogel algal como estrategia de riego". También se agradece al Ing. Agrónomo Luis Aguilera por el trabajo de terreno, el patrocinio de la llustre Municipalidad de Coquimbo y a las empresas regionales Exser Limitada, NT Ambiente E.I.R.L, Ecoprimitiva S.A. y a la planta de molienda de algas Kay Díaz González.

\section{REFERENCIAS}

Aguilera, L.E., Armas, C., y otros cuatro autores, Rainfall, microhabitat, and small mammals influence the abundance and distribution of soil microorganisms in a Chilean semi-arid shrubland, doi: 10.1016/j.jaridenv.2015.11.013, Journal of Arid Environments, 126, 37-46 (2016).

Apey, A., La fruticultura en Chile: tendencias productivas y su expresión territorial, Oficina de Estudios y Políticas Agrarias, Odepa, Ministerio de Agricultura (2019).

Badía, D., y Marti, C., Effect of Simulated Fire on Organic Matter and Selected Microbiological Properties of Two Contrasting Soils, doi: 10.1080/15324980390169064, Arid Land Research and Management, 17, 55-69 (2003).

Barata, A., Malfeito-Ferreira, M., y Loureiro, V., The microbial ecology of wine grape berries, doi: 10.1016/j.jfoodmicro.2011.11.025, International Journal of Food Microbiology, 153, 243-259 (2012). 
Chaves, M.M., Zarrouk, O., y otros cinco autores, Grapevine under deficit irrigation: hints from physiological and molecular data, doi:10.1093/aob/mcq030, Annals of Botany 105, 661-676 (2010).

Ferreyra, E.R., Sellés, V.G. y Sellés, M.I., Riego Deficitario Controlado en Uva de Mesa. Estrategias de Riego para Enfrentar Situaciones de Escasez de Agua en Frutales, Santiago, Chile, Instituto de Investigaciones Agropecuarias, Boletín INIA Nº 60 (2001).

Fisarakis, I.K., Stavrakas, D., Response of sultana vines (V. vinifera L.) on six rootstocks to NaCl salinity exposure and recovery, doi: 10.1016/S0378-3774(01)00115-9, Agricultural Water Management, 51, 13-27 (2001).

Gilbert, J., van der Lelie, D., y Zarraonaindia, I., Microbial terroir for wine grapes, doi: 10.1073/ pnas.1320471110. Proceedings of the National Academy of Sciences, 111, 5-6 (2014).

Hernández-Ochandia, D., y Rodríguez, M.G., Métodos para la extracción de nematodos presentes en suelos del agrupamiento Ferralítico en Cuba, Revista de Protección Vegetal, 31, 228-232 (2016).

Hien, N.Q., Nagasawa, N., y otros seis autores, Growth promotion of plants with depolymerized alginates by irradiation. Radiations Physics and Chemistry, 59, 97-101 (2000).

Holdt, S.L. y Kraan, S., Bioactive compounds in seaweed: functional food applications and legislation, doi: 10.1007/s10811-010-9632-5, Journal of Applied Phycology 23, 543-597 (2011).

Ishii, T., Aikawa, J., y otros cuatro autores, Effects of alginate oligosaccharide and polyamines on hyphal growth of vesicular-arbuscular mycorrhizal fungi and their infectivity of citrus roots. In: Proceedings of the 9th International Society of Citriculture Congress, 1030-1032 (2000).

Jaulneau, V. y Lafitte, C., Ulvan, a Sulfated Polysaccharide from Green Algae, Activates Plant Immunity through the Jasmonic Acid Signaling Pathway, doi: 10.1155/2010/525291, Journal of Biomedicine and Biotechnology 1-11 (2010).

Khan, W., Rayirath, U.P., y otros cuatro autores, Seaweed Extracts as Biostimulants of Plant Growth and Development, doi: 10.1007/s00344-009-9103-x, Journal of Plant Growth Regulation 28, 386-399 (2009).

Liu, D., y Howell, K., Community succession of the grapevine fungal microbiome in the annual growth cycle, doi: 10.1101/2020.05.03.075457, bioRxiv (2020).

Maestre, F.T., Delgado-Baquerizo, M., y otros veintisiete autores, Increasing aridity reduces soil microbial diversity and abundance in global drylands, doi: 10.1073/pnas.1516684112, Proceedings of the National Academy of Science of the United States of America, 112, 15684-15689 (2015).

Michalack, I., Chojnacka, K., y otros cuatro autores, Evaluation of supercritical extracts of algae as biostimulants of plant growth in Field Trials, doi: 10.3389/fpls.2016.01591, Frontiers in Plant Science, 7, 1591 (2016).

Milani, P., y França, D., y otros dos autores, Polymers and its applications in agriculture, doi: 10.1590/0104-1428.09316, Polímeros, 27, 256-266 (2017).

Moore, K.K., Using seaweed compost to grow bedding plants, BioCycle 45, 43-44 (2004).

ODEPA, Oficina de estudios y políticas agrarias, Panorama de la agricultura, (2017).

Parkinson, D., Gray, T.R.G., y Williams, S.T., Ecology of Soil Microorganisms. Blackwell, Oxford (1971).

Phillips, G.O. y Williams, P.A., Handbook of hydrocolloids, Second Edition, CRC Press, New York (2009).

Robic, A., Rondeau-Mouro C., y otros tres autores, Structure and interactions of ulvan in the cell Wall of the marine Green algae Ulva rotundata (Ulvales, Chlorophyceae), Carbohydrate Polymers, 77: 206-216, (2009).

Santibáñez, F., Santibáñez, P. y otros seis autores, Atlas del cambio climático en las zonas de regimen árido y semiárido, Universidad de Chile, Facultad de Ciencias Agronómicas, Centro de Agricultura y Medio Ambiente, (2014).

Sojka, R.E., y Entry, J.A., Influence of polyacrylamide application to soil on movement of microorganisms in runoff water, doi: 10.1016/S0269-7491(99)00194-3, Environmental Pollution, 108, 405-412 (2000).

Taban, M., y Movahedi, S.A., Effect of Aquasorb and Organic Compost Amendments on Soil Water Retention and Evaporation with Different Evaporation Potentials and Soil Textures, doi: 10.1080/00103620600770383, Communications in Soil Science and Plant Analysis, 37, 2031-2055 (2006).

Venegas, M., Matsuhiro, B., y Edding, M.E., Alginate composition of Lessonia trabeculata (Phaeophyta: Laminariales) in exposed and sheltered habitats, Botanica Marina, 36, 47-51 (1993).

Vitthalrao, S., Salunke, B.K., y otros dos autores, Studies on Amendment of Different Biopolymers in Sandy Loam and Their Effect on Germination, Seedling Growth of Gossypium herbaceum L, doi: 10.1007/s12010-010-9082-1, Applied Biochemical and Biotechnology, 163, 780-791 (2011).

Widmer, T., Mitkowski, N.A., y Abaw, G.S., Soil Organic Matter and Management of Plant-Parasitic Nematodes, Journal of Nematology, 34, 289-295 (2002).

Yu, J., Shi, A., y otros cinco autores, Superabsorbent polymer properties and concentration effects on water retention under drying conditions, doi: 10.2136/sssaj2016.07.0231, Soil Science Society of America Journal 81, 889-901 (2017). 